\title{
BMJ open Design of an instrument to measure alcohol-related psychosocial influences in the development of norms among 13-year-old to 17-year-old adolescents
}

\author{
Janina Hildebrand, ${ }^{1}$ Bruce Maycock, ${ }^{2}$ Sharyn Burns, ${ }^{1}$ Yun Zhao, ${ }^{2}$ Steve Allsop, ${ }^{3}$ \\ Peter Howat, ${ }^{1,4}$ Roanna Lobo ${ }^{1}$
}

To cite: Hildebrand $\mathrm{J}$, Maycock B, Burns S, et al. Design of an instrument to measure alcohol-related psychosocial influences in the development of norms among 13-year-old to 17-year-old adolescents. BMJ Open 2013;3:e003571. doi:10.1136/bmjopen-2013003571

- Prepublication history for this paper is available online. To view these files please visit the journal online (http://dx.doi.org/10.1136/ bmjopen-2013-003571).

Received 9 July 2013 Accepted 26 July 2013

For numbered affiliations see end of article.

Correspondence to Janina Hildebrand; j.hildebrand@curtin.edu.au

\section{ABSTRACT}

Introduction: Harmful drinking among young people is common in Australia and many other countries. Social norms and their influence on adolescents' alcohol consumption behaviours have received much research attention in recent years. However, there is limited understanding of how social norms related to alcohol are developed and transmitted across social networks and a specific tool that measures these constructs has yet to be developed. This paper outlines the rationale and protocol for the design and validation of a multidimensional survey instrument which measures the development and transmission pathways of alcohol-related norms among adolescents. A longer term aim is to apply the instrument in a respondentdriven sampling study with a large adolescent cohort. Methods and analysis: Social Cognitive Theory (SCT) and relevant literature will guide the design of the online survey instrument. Feedback from a practitioner-based stakeholder committee, academic expert panel reviews, focus groups and interviews with adolescents aged 13-17 years in Perth, Western Australia (WA) will serve to ascertain content and face validity. A test-retest will be conducted using a purposive sample of students $(n=400)$ at secondary schools in Perth. The instrument's psychometric properties will be analysed, including exploratory factor analyses, discriminant validity, internal consistency and test-retest reliability.

Ethics and dissemination: The results of this research will provide public health researchers and practitioners with a comprehensive standardised instrument to explore the characteristics of individuallevel and community-level social influences and norms associated with use of alcohol by adolescents and the routes through which these norms are transmitted. The data collected by the instrument is anticipated to inform the design of youth specific interventions with the potential to reduce alcohol-related harms. The Study findings will be disseminated widely through peer-reviewed publications and conference presentations. The study has received approval from the Curtin University Human Research Ethics Committee.

\section{ARTICLE SUMMARY}

Article focus

- Social norms and alcohol consumption by adolescents.

- Survey instrument development.

- Psychometric properties analysis.

Key messages

- A large body of research provides evidence for the influence of social norms on risky drinking behaviour among young people.

- There is a lack of research examining a broad range of mediating psychosocial factors to identify risk and protective factors in shaping alcohol-related norms among adolescents.

- The proposed survey instrument will provide a means to measure individual alcohol-related attitudes and beliefs, perceived collective expectations around drinking alcohol, as well as media influence and social connections to family, peers, school and the wider community to examine their role in the development and transmission of alcohol norms.

Strengths and limitations of this study

- Use of a mixed-method research approach consisting of qualitative and quantitative methods to develop a valid and reliable survey instrument measuring a broad range of psychosocial constructs related to adolescent alcohol norm development.

- Challenges in recruiting a large enough representative sample that will complete the survey for both the test and retest.

\section{INTRODUCTION}

Young people in many developed countries are increasingly drinking at levels that put them at risk of harm from alcohol-related disease or injury. ${ }^{1-4}$ In Australia, young people aged 18-25 years have the highest levels of alcohol consumption and are at high risk of incurring a range of alcohol-related harms, 
including road trauma, violent assault, sexual coercion, drowning and suicide ${ }^{56}$ In 2010, $18 \%$ of Australian youth aged 14-19 years consumed alcohol at risky levels (10 drinks a day for males, and 5-6 drinks a day for females) at least weekly. ${ }^{5}$

Beliefs, attitudes and behaviours associated with alcohol consumption are established in childhood and early adolescence. ${ }^{7}$ Parental attitudes and behaviours, interaction with peers, alcohol availability and exposure to alcohol advertising are among the key psychosocial influences on drinking. ${ }^{8-11}$ Social norms, as well as the expectations about acceptable behaviour that is shared by a group of people, ${ }^{12}$ play a powerful role in influencing when, where, how often and at what level drinking is considered acceptable. ${ }^{13}$ Social norms are typically categorised into descriptive norms, the perception of what others do and injunctive norms, the extent to which others approve or disapprove of a given behaviour. ${ }^{14} 15$ These concepts have commonly been used to explain drinking behaviour among young people. ${ }^{16-19}$

While parental and peer influences appear to have an impact on adolescent drinking behaviours, peer influences tend to be stronger predictors of alcohol use, as children grow older and spend more time with their friends. A notable shift from norms transmitted via institutions (eg, church, school) to those transmitted via individual-focused routes (eg, social networking media) highlights the importance of peer influence in normative development processes during adolescence. ${ }^{12}$ However, recent research suggests that parental behaviours, attitudes and values continue to influence adolescent behaviour including alcohol use. ${ }^{20} \mathrm{~A}$ systematic review of longitudinal studies examining parenting factors related to adolescent drinking reported that parental modelling of drinking behaviour, disapproval of adolescent drinking, rules about alcohol and general discipline, monitoring, alcohol-specific and general communication, quality of parent-child relationship, family conflict, and parental support and involvement were protective of adolescent drinking initiation and levels of alcohol use. ${ }^{11}$ However, parental modelling of drinking and permissiveness or approval of adolescent drinking have been found to increase adolescent drinking behaviour. ${ }^{21-23}$

International research conducted with high school and college students provides significant evidence that risky youth drinking is influenced by peer expectations and associations and consumption of alcohol at a young age. ${ }^{19}$ 2425 A large number of studies examining adolescents' and young adults' perceptions of normative behaviour indicate that young people generally overestimate the prevalence and approval of peer drinking. ${ }^{15}{ }^{19} \quad 26-28$ Research demonstrates that an overestimation of alcohol consumption by peers as well as their approval of drinking, particularly those held in high esteem, has the effect of increasing personal consumption. ${ }^{14-16} 29$ The desire to conform with peer influences increased personal alcohol consumption, ${ }^{24}{ }^{30}$ although adolescents make exaggerated claims about their independence from social network influence ${ }^{31}$ and report being aware of the risks associated with drinking. ${ }^{32}$ However, overestimation of peer drinking may contribute to adolescents viewing their own drinking as normal and unproblematic, thereby 'normalising' excessive personal consumption. ${ }^{14}$

The proximity and significance of social groups plays an important role in normative influence processes. ${ }^{33}$ However, there may be a conflict between norms of distal groups (eg, generalised society norms) and norms held by an individual or an individual's proximal reference groups (eg, friends and family) as there are inconsistent findings of the strength of influence different groups have on drinking behaviour. ${ }^{12}{ }^{34}$ While normative perceptions of close peers appear to be more likely to influence drinking than those of groups young people feel less connected to (eg, typical student), ${ }^{14} 28 \mathrm{a}$ study of US college athletes found that not only close friends but also those whom participants aspired to be like but may have been distal from the immediate group (eg, sporting role models) influenced perceived norms and behaviour. ${ }^{16}$

Alcohol expectancies, as well as beliefs about the positive or negative effects of alcohol, are shaped at an early age through various social influences, including culture, family and peers. ${ }^{35}$ Positive expectancies, the belief that alcohol consumption will result in desirable effects, such as peer approval or feeling more relaxed, appear to increase as children get older ${ }^{3637}$ and have been shown to predict drinking initiation in adolescents and continued drinking over time. ${ }^{38} 39$ Besides higher levels of perceived parental and peer drinking and approval of alcohol use, exposure to alcohol advertising has been associated with more favourable alcohol expectancies among adolescents. ${ }^{9} 104041$ Cross-sectional and longitudinal studies have shown that exposure to and positive attitudes towards alcohol advertising have been associated with increased drinking intentions and behaviours. ${ }^{42-45}$

Although the literature clearly indicates the role of peers, parents and the media in shaping the norms associated with drinking, adolescents' perceptions of alcohol use and approval of drinking within an Australian context have not been widely studied. ${ }^{46}$ The majority of studies exploring social norms have been conducted with US and European high school and college students and there is a lack of evidence about how these norms are transmitted within the community, as well as between family members and friends. It remains unclear which reference groups are stronger predictors of risky drinking, how youth with different levels and types of connection to others perceive behavioural norms and how young people reconcile conflicting injunctive norms of different reference groups. Other relevant normative constructs such as age, quantum and sequencing norms (when and how many times an event should occur), as well as sanctions involved for violating group norms,${ }^{12}$ have not been widely explored in the adolescent alcohol literature except in relation to parents. ${ }^{21}$ 
Similarly, the majority of studies investigating the impact of alcohol advertising have been conducted in the USA, with a focus on television or magazine advertising and its influence on drinking outcomes. Limited research has explored the impact of alcohol promotion exposure at social events or on the internet and its influence on norm development, ${ }^{9}$ or the interactions between advertising and other psychosocial influences. ${ }^{47}$

Understanding the direct link between various psychosocial influences and alcohol-related attitudes and behaviours is critical to determine what types of normative interventions may be appropriate or effective. Currently, there is no known comprehensive standardised instrument that can validly and reliably measure these constructs. This article describes the proposed research design and procedures to develop and validate an instrument to gather information about how alcohol-related beliefs, attitudes and social norms develop and are shared, as well as the associated role of parents, peers, media and social networks. This study forms part of a larger research project which will involve administration of the final survey using respondent-driven sampling with a large adolescent cohort. This, in turn, will help clarify the development of alcohol-related norms among young people in Australia.

\section{METHODS AND ANALYSIS}

\section{Study objectives}

The research objectives for this study are to develop and validate a standardised online survey instrument that will (1) identify common alcohol-related social influences, norms and beliefs among adolescents; (2) clarify the process and pathways through which pro-alcohol norms are transmitted to adolescents; (3) describe the characteristics of social connections that contribute to the transmission of alcohol norms and (4) identify the influence of alcohol marketing on adolescent norm development.

\section{Study design}

The instrument development will consist of a mix of qualitative and quantitative methods. The purpose of the qualitative stage is to elicit themes and subthemes to generate item measures, based on a theoretical framework, and review of the research literature, along with consultations with experts and the relevant target group. The quantitative component will include the administration of the survey with a purposive sample of adolescents to ensure that it will provide valid and reproducible data in the context in which it will be administered. Based on the synthesised information collected through the literature review and theoretical framework, stakeholder committee feedback, expert panel reviews, focus groups and interviews, an appropriate instrument will be designed and assessed for its psychometric properties. The analysis will consist of exploratory factor analyses, discriminant validity, internal consistency and test-retest reliability. Figure 1 summarises the process for the proposed survey development, data collection and analysis.

\section{Research setting}

The research will occur within Perth, WA. Participants for focus groups and interviews will be recruited purposively via community sporting clubs and youth organisations in Perth. These settings were chosen as they represent venues in which youth can be accessed consistently. A test-retest will be conducted of the developed instrument with students of secondary schools across Perth. Schools will be selected to enable repeated access to a large and stable sample within a short period of time. Clubs, organisations and schools will be selected across suburbs with varying socioeconomic status (SES) to ensure that the sample is representative of the target group.

\section{Inclusion criteria}

For the purpose of recruiting adolescents for focus groups and one-on-one interviews, community sporting clubs and youth organisations will be eligible to participate in the study if they are either a Perth-based community-level, non-professional sports club or community organisation offering sports groups, services or activities targeting adolescents aged 13-17 years. Schools eligible to participate in the test-retest will be located in Perth and be able to provide repeated access to students of age 9-12 years over two time intervals, approximately 2 weeks apart.

Sports club and community organisation members as well as students will be eligible to participate if they are aged between 13 and 17 years, live in Perth, speak English and are current members or students of the club, programme or school selected for recruitment.

\section{Instrument development}

In the development of the instrument, the underlying theoretical framework will be compared with the reviewed literature. The findings of the literature review will then be synthesised with the theoretical elements to form the instrument constructs. ${ }^{48}$

\section{Theoretical framework}

Social Cognitive Theory (SCT) ${ }^{49}$ will guide the development of this instrument. SCT assumes that social behaviours are learnt through observation of other people's behaviour and this behaviour is consequently modelled, reinforced and internalised. ${ }^{50}$ Applied to alcohol consumption, these learning processes include exposure to the drinking behaviour of significant others, including parents and peers, which is imitated and positively reinforced. The perceived acceptability of drinking behaviours may also stem from modelling by or communication with other individuals or groups a young person is connected to in the wider community. Similarly, alcohol use portrayed in the media via role models, such as sports or music idols, can play a part in 


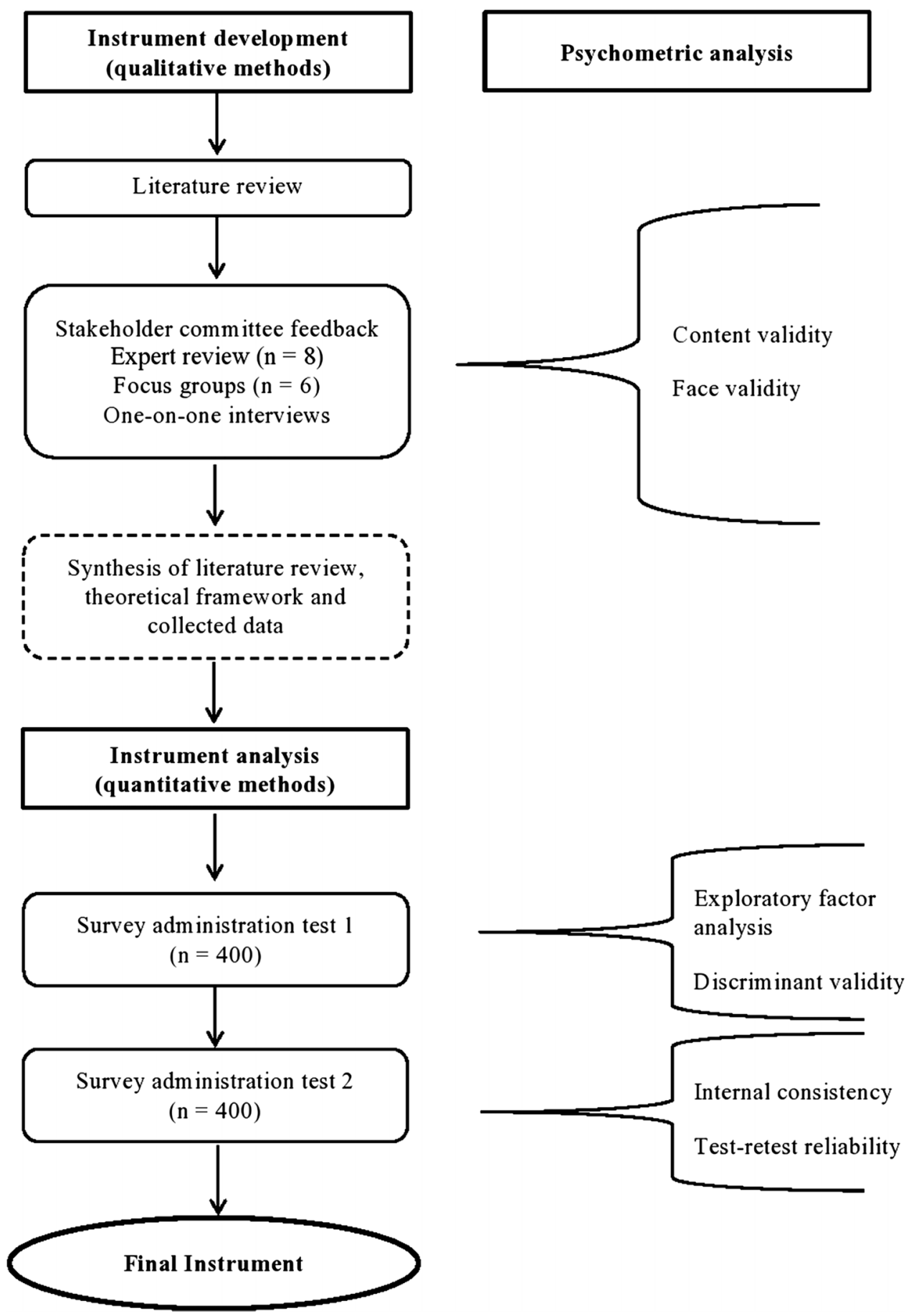

Figure 1 Proposed survey instrument development and analysis process.

shaping adolescents' perceptions and behaviours. By pointing to the interactions among various variables to be analysed, SCT will guide the process of selecting instrument items and developing focus group interview schedules.

\section{Literature review}

A comprehensive literature review will be undertaken to identify the main areas of inquiry and existing scales, followed by generation of the instrument items. The
Pubmed, Psychinfo and Informit databases and websites containing tool compilations will be reviewed, including the USA National Library of Medicine-Health Services and Sciences Research Resources and the Alcohol and Drug Abuse Institute Library-Substance Use Screening \& Assessment Instruments Database. Search terms will include various combinations of the following terms: adolescent, beliefs, attitudes, expectancies, perceptions, values, norms, approval, acceptance, permissibility, rules, sanctions, peers, friends, siblings, parents, school, 
community, connectedness, identity, alcohol advertising/advertisement/marketing, alcohol consumption, risky/binge drinking and others.

The initial review will include publications between 2002 and 2012 and a manual reference list search of retrieved publications. Self-report questionnaires published in the English language that target young people aged $12-17$ years and aim to measure relevant constructs will be eligible for inclusion. Widely used and validated scales which allow comparison with national studies and other research will be favoured. Short scales with simple response options that can be included in their entirety will be given preference to reduce subject burden. Adult-focused or clinical scales will be excluded.

The literature review will seek to identify instruments that link to the SCT and assess the key constructs: personal drinking attitudes, beliefs, intentions and behaviour; peer and parental descriptive and injunctive norms; expectations of sanctions that could be imposed by parents and peers; ease of access to alcohol; social networks and connectedness to family, school, community and peers; perceived social identity with peers; and media influence. Demographic information will also be sought. Table 1 summarises the proposed key constructs and corresponding conceptual definitions that link in with the theoretical framework and preliminary review of the literature.

\section{Stakeholder committee}

A stakeholder committee will be established for this study comprising senior government and nongovernment representatives of alcohol-related and youth-related services, such as health, education, police and sports. The aim of the committee is to provide practice-based input to the development of the instrument and to assist with identifying and facilitating access points in the community to recruit study participants.

\section{Expert review}

Expert opinion will be sought for content validation, the extent to which the instrument measures a complete range of attributes and is representative of the construct of interest, ${ }^{48}$ using a purposively selected sample of experts $(n=8)$ in the areas of health promotion, psychology, education, alcohol research and biostatistics at Curtin University. It is recommended that for content validity at least seven experts are consulted. ${ }^{51}$ The selected scales will be subject to review by the expert panel at several stages during instrument development to obtain qualitative comments regarding the devised items and the overall tool. Based on the comments, the selected scales will be modified and items created for constructs for which no relevant scales can be located.

\section{Focus group interviews}

Focus group interviews will be conducted to inform thecontent and design of the instrument with a purposive sample of adolescents aged 13-17 years living in Perth.
Table 1 Proposed key dimensions, constructs and corresponding conceptual definitions

\begin{tabular}{ll}
\hline Dimension & Construct \\
\hline Behaviours & Drinking \\
& behaviour \\
& Experienced \\
& alcohol related \\
harms
\end{tabular}

Individual

beliefs and

Drinking

attitudes

intention

Conceptual definition

Individual's reported use of alcohol

The acute and long-term negative consequences of alcohol use ${ }^{60}$

A person's perceived probability that they will conduct a certain behaviour $^{61}$

Drinking attitudes

Attitude is defined as the positive or negative evaluation of a specific object ${ }^{62}$

Alcohol expectancies

Access to alcohol

Social norms Descriptive norms The beliefs about positive or negative effects of alcohol ${ }^{36}$ Source and ease of obtaining alcohol The perception of the prevalence of other's actual behaviour $^{63}$

Injunctive norms The perception of the extent to which others approve or disapprove of a given behaviour ${ }^{63}$ Perceived social The enforcement of sanctions socially approved behaviour by rewarding conformity and punishing non-conformity ${ }^{64}$

Media influence Alcohol The promotion of promotion alcohol brands and products by alcohol companies via the media

Social Social The perception of connectedness connectedness feeling a sense of belonging and an existing bond to other persons, groups or institutions ${ }^{65}$

Group identity The perceived similarity to a social group ${ }^{66}$ 
additional items if necessary. ${ }^{48}$ The interview schedule will be based on SCT to investigate the participant's attitudes and beliefs related to drinking, focusing on perceptions of parental and peer behaviour, attitudes, expectations and sanctions, social connections and awareness of alcohol marketing using open-ended questions. Personal preferences regarding survey participation will also be explored and participants will be asked to complete a brief demographics questionnaire.

Six to eight focus groups will be conducted with each consisting of 6-10 participants and with an equal balance of gender, age groups, SES areas and previous drinking experience. A range of youth organisations will be approached to explain the study and gain management consent for recruitment. Focus groups will be scheduled at a time and location convenient to participants.

To ensure consistency, focus group facilitators will receive training from an experienced staff member. The discussions will be audio-taped and transcribed. The qualitative data obtained from the focus groups will be analysed using the software package NVivo V.9 to identify common themes which will be reflected in the instrument content and design. For inter-rater reliability, themes from the focus group transcripts will be identified independently by two research team members. The results will be used to modify existing scales by adapting content and wording to be more target group-specific and to generate new items for constructs where no relevant scales are located.

\section{Instrument format}

A self-complete online survey will be used for data collection. The online survey format was chosen for several reasons. Online surveys may increase the likelihood of higher response rates, ${ }^{52}$ in particular among populations who are acquainted with using the Internet, such as adolescents. ${ }^{53}$ Collecting data with online surveys is also less invasive and more likely to safeguard anonymity. Using an online survey in this study may potentially generate higher quality data. The survey includes questions on sensitive topics, for example respondents' drinking attitudes and behaviours. This may potentially cause social desirability response bias, which occurs when participants respond in a way they believe is more acceptable to others or conform to perceived group expectations and is frequently reported in alcohol research. ${ }^{52}$ To reduce the likelihood of this type of bias occuring, participants will receive verbal and written information of the completed surveys being de-identified and the study results being reported in aggregate format only. Using an online format allows participants to enter their responses directly into the computer. This has the advantage that participant names and responses are kept private and confidential as they cannot be linked or be seen by anyone apart from the researcher. Finally, online surveys can decrease implementation costs, improve questionnaire formatting and eliminate data entry decreasing processing costs and allowing for faster data collection. ${ }^{52}$

\section{Instrument pretest}

To assess face validity, the extent to which an instrument appears to measure the construct, ${ }^{51}$ one-on-one interviews will be conducted with a convenience sample of 10 adolescents aged 13-17 years living in Perth, using the same recruitment methods and venues as for the focus groups. Participants will be asked to complete the survey and then asked a number of questions to assess the instrument's readability, clarity of language, style, formatting and usability. This phase will consist of a cyclic process of interviewing a young person, amending the survey according to the respondent's feedback and further testing with other participants. This process will be continued until the research team feels confident that the survey items are unambiguous, appropriate and acceptable and that the design and layout are suitable for the target group.

To further ensure that the survey's language and format are appropriate for the target group, the Flesch Reading Ease (FRE) formula ${ }^{54}$ will be used to assess the reading level. The FRE determines a reading grade level based on word and syllable counts and is considered to be the most widely used scale. ${ }^{55}$ An FRE score exceeding 60 with a maximum Flesch Kinkaid Grade Level of seven will be considered acceptable.

\section{Instrument testing}

Sample selection

A purposive sample of at least 400 adolescents aged 13-17 years will be recruited from at least six mixed-gender and single-gender secondary schools in varying SES areas across Perth. To ensure that an equal proportion of gender and age groups is represented in the sample, one entire year 9 (13-14 years), year 10 (1415 years), year 11 (15-16 years) and year 12 (1617 years) group will be recruited, with 1-2 year groups per school.

\section{Sample size}

The required sample size of studies assessing measurement properties of instruments has been proposed as a minimum of 50 participants. ${ }^{56} \mathrm{~A}$ range of recommendations for the minimum necessary sample size has been made for factor analyses, ranging from 100 to 1000 or more. For example, a sample size of 300 is considered to be good and a sample size of 500 is regarded as very good. ${ }^{57}$ In this study, the research team will recruit at least 400 participants. $^{57}$

\section{Data collection procedures}

Prior to the collection of data, a letter describing the study and requesting permission to survey the students will be posted and emailed to the principals of $50 \mathrm{sec}-$ ondary schools in Perth, and followed up by a phone call 2 weeks after the first contact. After gaining approval 
from school principals, a staff member at each school will be nominated as the school's contact person for promotion and implementation of the study and for gaining parental consent.

Administration of the survey will occur twice, 2 weeks apart. The time interval between assessments is important for determining test-retest reliability; a period of $1-2$ weeks is recommended. This interval is not too brief, hence preventing participants from remembering their previous responses, but also not too long, not allowing for actual change in attitudes and behaviours. ${ }^{48}$ Surveys will be conducted at a time convenient to the schools. Participants will complete the surveys electronically, in school computing laboratories or on their own laptops.

\section{Data analysis}

Quantitative data will be analysed using the Statistical Package for Social Science, V.18.0. Descriptive statistics will be calculated for variables of interest. Exploratory factor analysis with different factor extraction and rotation methods will determine the dimensional factor structure of alcohol-related social influences and norms among adolescents depicted by the proposed instrument. ${ }^{58}$ To test the discriminant validity of the instrument, the extent to which each subscale represents a unique dimension, and the correlations between the obtained subscales and different gender, age, ethnicity and alcohol consumption groups will be computed. ${ }^{58}$ The internal consistency of the instrument, as well as the degree to which items in a scale are correlated, will be determined by Cronbach's $\alpha(\alpha)$ coefficients with an accepted minimal standard of $\alpha=0.7{ }^{58}$ Test-retest reliability will be assessed to ascertain the degree to which the instrument will repeatedly provide similar responses in a stable sample using Pearson's correlation coefficient (r) and the Intra-class Correlation Coefficient (ICC). The reliability is considered to be better when $\mathrm{r}$ and ICC exceed $0.6{ }^{59}$ The relationship between the obtained subscales in the proposed instrument and demographic characteristics will be investigated using independent samples-t test or one-way ANOVA to detect significant difference between groups.

\section{ETHICS AND DISSEMINATION}

Prior to study enrolment, all adolescents will receive verbal and written information about the study, stipulating the study purpose and type of involvement required from them along with the participants' rights, including that all information provided will be treated in a nonidentifiable, confidential manner. Only adolescents for whom active parental consent is obtained will be eligible to take part in the study. For privacy protection, this study will use a third party server with encryption software and password protection. Participants' IP address will not be stored in the survey. To acknowledge participation, incentives in the form of movie tickets will be offered to the focus group and interview participants.
Participating schools will be offered a small honorarium in the form of a gift voucher valued at $\$ 200$.

There is a lack of research evidence on which social cognitive factors are most influential in shaping the normative understandings and behaviours associated with alcohol consumption among adolescents and few studies have analysed the interactions of multiple influences simultaneously. ${ }^{9} 104147$ Examining the mediating factors of alcohol consumption among adolescents is essential to understanding the underlying mechanisms in this process. The results of this research will provide public health researchers and practitioners with a comprehensive standardised instrument to explore the characteristics of a complex range of psychosocial influences and norms associated with adolescent alcohol use and the routes through which these norms are transmitted. It is anticipated that employing an instrument that allows accurate measurement of these constructs will improve existing knowledge. This may guide the development of appropriate and evidence-based health initiatives that have the potential to reduce risk factors or enhance protective factors related to youth risky drinking.

The developed instrument will be used in a subsequent respondent-driven sampling study to explore the role of individual beliefs, attitudes and perceived collective expectations around drinking alcohol, as well as media influence and social connections to family, peers, school and the wider community in the development and transmission of alcohol-related social norms. The data will then be used to form the basis of future research projects that will utilise the instrument to guide community interventions. Additional dissemination activities will include presentations to local and international academics and practitioner audiences, and publications in academic and practice journals.

\section{Author affiliations}

${ }^{1}$ Western Australian Centre for Health Promotion, Curtin University, Perth, Western Australia, Australia

${ }^{2}$ School of Public Health, Curtin University, Perth, Western Australia, Australia ${ }^{3}$ National Drug Research Institute, Curtin University, Perth, Western Australia, Australia

${ }^{4}$ Centre for Behavioural Research in Cancer Control, Curtin University, Perth, Western Australia, Australia

Acknowledgements The authors would like to thank Satvinder Dhaliwal, Jonathan Hallett and Jude Comfort for their contributions to the design of the overarching respondent-driven sampling study; they acknowledge the following stakeholder committee members for their support of and involvement in this research: Mr Gary Kirby, Drug and Alcohol Office; Mr Bruno Faletti, Department of Education and Training; Mr Graham Brimage, Department of Sport and Recreation; Mr Rob Thompson, Western Australian Sports Federation; and Mr Barry Newell, Western Australia Police.

Contributors BM, SA, PH, SB and RL designed the overarching respondent-driven sampling study and secured the funding for this project. $\mathrm{J} \mathrm{H}$ led the design of this study and drafted the manuscript. BM, SB, SA, PH and $R L$ were responsible for editing and guidance on the paper and development of the research methods. YZ developed the proposed statistical analyses. All authors were responsible for critically revising the paper and approved the final version of this paper for submission.

Funding This work is supported by a Healthway (the Western Australian Health Promotion Foundation) research project grant [grant number 20331]. 
Competing interests None.

Ethics approval Curtin University Human Research Ethics Committee [approval number: HR-25/2012].

Provenance and peer review Not commissioned; internally peer reviewed.

Open Access This is an Open Access article distributed in accordance with the Creative Commons Attribution Non Commercial (CC BY-NC 3.0) license, which permits others to distribute, remix, adapt, build upon this work noncommercially, and license their derivative works on different terms, provided the original work is properly cited and the use is non-commercial. See: http:// creativecommons.org/licenses/by-nc/3.0/

\section{REFERENCES}

1. Kuntsche E, Rehm J, Gmel G. Characteristics of binge drinkers in Europe. Soc Sci Med 2004;59:113-27.

2. Sproston K, Primatesta P. Health insurance for England 2002: Volume 1: the health of children and young people. London: The Stationery Office, 2003

3. Wilkins C, Casswell S, Bhatta K, et al. Drug use in New Zealand: National Surveys Comparison 1998 \& 2001. Auckland: Alcohol and Public Health Research Unit, 2002.

4. Naimi TS, Brewer RD, Mokdad A, et al. Binge drinking among US adults. JAMA 2003;289:70-5.

5. Australian Institute of Health and Welfare [AIHW]. 2010 National drug strategy household survey report. Drug Statistics Series No. 25. Canberra: AlHW, 2011.

6. Australian Institute of Health and Welfare [AlHW]. Young Australians: their health and wellbeing 2011. Canberra: AlHW, 2011.

7. Cranford JA, Zucker RA, Jester JM, et al. Parental alcohol involvement and adolescent alcohol expectancies predict alcohol involvement in male adolescents. Psychol Addict Behav 2010;24:386-96.

8. Cortese G. Identities, subjectivities and language in juvenile alcohol issues. Int J Children's Rights 2010;18:233-52.

9. Dal Cin S, Worth KA, Gerrard M, et al. Watching and drinking: expectancies, prototypes, and friends' alcohol use mediate the effect of exposure to alcohol use in movies on adolescent drinking. Health Psychol 2009;28:473-83.

10. Martino SC, Collins RL, Ellickson PL, et al. Socio-environmental influences on adolescents' alcohol outcome expectancies: a prospective analysis. Addiction 2006;101:971-83.

11. Ryan S, Jorm A, Lubman D. Parenting factors associated with reduced adolescent alcohol use: a systematic review of longitudinal studies. Aust N Z J Psychiatry 2010;44:774-83.

12. Liefbroer AC, Billari FC. Bringing norms back in: $A$ theoretical and empirical discussion of their importance for understanding demographic behaviour. Popul Space Place 2010;16:287-305.

13. Ahlström S, Österberg E. International perspectives on adolescent and young adult drinking. Alcohol Res Health 2004/2005;28:258-68.

14. Borsari $B$, Carey KB. Descriptive and injunctive norms in college drinking: a meta-analytic integration. J Stud Alcohol 2003;64:331-41.

15. Borsari B, Carey KB. Peer influences on college drinking: a review of the research. J Subst Abuse 2001;13:391-424.

16. Dams-O'Connor K, Martin JL, Martens MP. Social norms and alcohol consumption among intercollegiate athletes: the role of athlete and non-athlete reference groups. Addict Behav 2007;32:2657-66.

17. LaBrie JW, Hummer JF, Neighbors $\mathrm{C}$, et al. Whose opinion matters? The relationship between injunctive norms and alcohol consequences in college students. Addict Behav 2010;35:343-9.

18. Oostveen $T$, Knibbe $R$, De Vries $H$. Social influences on young adults' alcohol consumption: norms, modeling, pressure, socializing, and conformity. Addict Behav 1996;21:187-97.

19. Stappenbeck CA, Quinn PD, Wetherill RR, et al. Perceived norms for drinking in the transition from high school to college and beyond. J Stud Alcohol Drugs 2010;71:895-903.

20. Wood MD, Read JP, Mitchell RE, et al. Do parents still matter? Parent and peer influences on alcohol involvement among recent high school graduates. Psychol Addict Behav 2004;18:19-30.

21. Foley Kl, Altman D, Durant Rh, et al. Adults' approval and adolescents' alcohol use. J Adolesc Health 2004;35:345.e17-26.

22. Van Der Vorst $\mathrm{H}$, Burk W, et al. The role of parental alcohol-specific communication in early adolescents' alcohol use. Drug Alcohol Depend 2010;111:183-90.

23. Livingston J, Testa M, Hoffman J, et al. Can parents prevent heavy episodic drinking by allowing teens to drink at home? Addict Behav 2010;35:1105-12.
24. Corbin WR, Iwamoto DK, Fromme K. Broad social motives, alcohol use, and related problems: mechanisms of risk from high school through college. Addict Behav 2011;36:222-30.

25. Zufferey A, Michaud $P$, Jeannin A, et al. Cumulative risk factors for adolescent alcohol misuse and its perceived consequences among 16-20 year old adolescents in Switzerland. Prev Med 2007;45:233-9.

26. Coleman L, Cater S. Underage 'binge' drinking: a qualitative study into motivations and outcomes. Drugs Educ Prev Policy 2005;12:125-36.

27. Larimer ME, Kaysen DL, Lee CM, et al. Evaluating level of specificity of normative referents in relation to personal drinking behavior. J Stud Alcohol Drugs 2009;(Supp 16):115-21.

28. Pedersen E, Neighbors C, LaBrie JW. College students' perceptions of class year-specific drinking norms. Addict Behav 2010;35:290-3.

29. Neighbors C, Lee CM, Lewis MA, et al. Are social norms the best predictor of outcomes among heavy-drinking college students? J Stud Alcohol Drugs 2007;68:556-65.

30. Bot S, Engels R, Knibbe R, et al. Friend's drinking behaviour and adolescent alcohol consumption: the moderating role of friendship characteristics. Addict Behav 2005;30:929-47.

31. Cotterell J. Social networks in youth and adolescence. 2nd edn. London: Routledge, 2007.

32. Gerrard M, Gibbons FX, Benthin AC, et al. A longitudinal study of the reciprocal nature of risk behaviors and cognitions in adolescents: what you do shapes what you think, and vice versa. Health Psychol 1996;15:344-54.

33. Neighbors C, LaBrie JW, Hummer JF, et al. Group identification as a moderator of the relationship between perceived social norms and alcohol consumption. Psychol Addict Behav 2010;24:522-8.

34. Lewis MA, Neighbors C. Gender-specific misperceptions of college student drinking norms. Psychol Addict Behav 2004;18:334-9.

35. Dunn ME, Goldman MS. Validation of multidimensional scaling-based modeling of alcohol expectancies in memory: age and drinking-related differences in expectancies of children assessed as first associates. Alcohol Clin Exp Res 2000;24:1639-46.

36. Miller PM, Smith GT, Goldman MS. Emergence of alcohol expectancies in childhood: a possible critical period. J Stud Alcohol Drugs 1990;51:343-9.

37. Schell TL, Martino SC, Ellickson PL, et al. Measuring developmental changes in alcohol expectancies. Psychol Addict Behav 2005;19:217-20.

38. Killen JD, Hayward C, Wilson DM, et al. Predicting onset of drinking in a community sample of adolescents: the role of expectancy and temperament. Addict Behav 1996;21:473-80.

39. Smith GT, Goldman MS, Greenbaum PE, et al. Expectancy for social facilitation from drinking: the divergent paths of high-expectancy and low-expectancy adolescents. J Abnorm Psychol 1995;104:32-40.

40. Anderson P, de Bruijn A, Angus K, et al. Impact of alcohol advertising and media exposure on adolescent alcohol use: a systematic review of longitudinal studies. Alcohol Alcohol 2009;44:229-43.

41. Cumsille PE, Sayer AG, Graham JW. Perceived exposure to peer and adult drinking as predictors of growth in positive alcohol expectancies during adolescence. J Consult Clin Psych 2000;68:531-6.

42. Chen MJ, Grube JW, Bersamin M, et al. Alcohol advertising: What makes it attractive to youth? J Health Commun 2005;10:553-65.

43. Fleming K, Thorson E, Atkin CK. Alcohol advertising exposure and perceptions: links with alcohol expectancies and intentions to drink or drinking in underaged youth and young adults. J Health Commun 2004:9:3-29.

44. Hurtz SQ, Henriksen L, Wang Y, et al. The relationship between exposure to alcohol advertising in stores, owning alcohol promotional items, and adolescent alcohol use. Alcohol Alcohol 2007;42:143-9.

45. Smith LA, Foxcroft DR. The effect of alcohol advertising, marketing and portrayal on drinking behaviour in young people: Systematic review of prospective cohort studies. BMC Public Health 2009;9.

46. Hughes $\mathrm{C}$, Julian R, Richman M, et al. Harnessing the power of perception: reducing alcohol-related harm among rural teenagers. Youth Stud Aust 2008;27:26-35.

47. Kinard BR, Webster C. The effects of advertising, social influences, and self-efficacy on adolescent tobacco use and alcohol consumption. J Consum Aff 2010;44:24-43.

48. Streiner DL, Norman GR. Health measurement scales: a practical guide to their development and use. 4th edn. Oxford: Oxford University Press, 2008

49. Bandura A. Social foundations of thought and action: a social cognitive theory. Prentice Hall, 1986.

50. Nutbeam D, Harris E, Wise M. Theory in a nutshell: a practical guide to health promotion theories. 3rd edn. Sydney: McGraw-Hill, 2010.

51. DeVon HA, Block ME, Moyle-Wright $P$, et al. A psychometric toolbox for testing validity and reliability. J Nurs Scholarsh 2007;39:155-64.

52. Dillman DA. Mail and internet surveys: the tailored design method. 2nd edn. New York: John Wiley \& Sons, Inc., 2000. 
53. Australian Bureau of Statistics. Household use of information technology, Australia, 2010-11. Cat. no. 8146.0. Canberra: ABS, 2011.

54. Flesch R. A new readability yardstick. J Appl Psychol 1948;32:221-33.

55. Ley $\mathrm{P}$, Florio $\mathrm{T}$. The use of readability formulas in healthcare. Psychol Health Med 1996;1:7-28.

56. Terwee CB, Bot SDM, de Boer MR, et al. Quality criteria were proposed for measurement properties of health status questionnaires. J Clin Epidemiol 2007;60:34-42.

57. MacCallum RC, Widaman KF, Zhang S, et al. Sample size in factor analysis. Psychol Methods 1999;4:84-99.

58. Coakes SJ, Steed LG, Ong C. SPSS: analysis without Anguish (Version 16.0 for Windows). Milton, QLD: John Wiley \& Sons, 2009.

59. Wuyi Z, Huang B. Analysis on the reliability and validity of a questionnaire. Stat Info Forum 2005;20:11-15.

60. National Health and Medical Research Council. Australian guidelines to reduce health risks from drinking alcohol. Canberra: Commonwealth of Australia, 2009:1-179.
61. Fishbein M, Ajzen I. Belief, attitude, intention, and behavior: an introduction to theory and research. Addison-Wesley, 1975.

62. Eagly A, Chaiken S. Attitude strength, attitude structure and resistance to change. In: Petty R, Kosnik J.eds Attitude strength. Mahwah, NJ: Erlbaum, 1995:413-32.

63. Cialdini RB, Reno RR, Kallgren CA. A focus theory of normative conduct: recycling the concept of norms to reduce littering in public places. J Pers Soc Psychol 1990;58:1015-26.

64. Blake J, Kingsley D. Norms, values, and sanctions. In: Fans RE.ed. Handbook of modern sociology. Chicago: Rand McNally, 1964.

65. Bernat DH, Resnick MD. Connectedness in the lives of adolescents. In: DiClemente RJ, Santelli JS, Crosby RA.eds. Adolescent health: understanding and preventing risk behaviors. San Francisco: Jossey-Bass, 2009

66. Rimal RN, Real K. How behaviors are influenced by perceived norms: a test of the theory of normative social behavior. Commun Res 2005;32:389-414. 